\section{Bombardment of Nitrogen and Oxygen with Protons}

A REACTION of considerable interest in connexion with Bethe's theory of energy production in the stars ${ }^{1}$ is that involving the capture of protons by the isotope of nitrogen ${ }^{14} \mathrm{~N}$.

$$
{ }^{14} \mathrm{~N}+{ }^{1} \mathrm{H} \rightarrow{ }^{15} \mathrm{O}+h v
$$

since this process is one of those involved in his cyclical scheme of nuclear processes. The occurrence of this process was detected by measuring the radioactivity produced in targets of sodium nitride (found to be one of the few compounds of nitrogen that is stable under bombardment). The period of the radioactivity was two minutes, in agreement with the known value ${ }^{2}$ for ${ }^{15} \mathrm{O}$, and the excitation function for the reaction is as shown in Curve $A$ in the accompanying graph. Some slight evidence of resonance features is present, but the low yield of the active product prevented very accurate measurement. The yield was found to be $1.5 \times 10^{-11}$ positrons per proton of energy $0.96 \times 10^{6} \mathrm{ev}$.

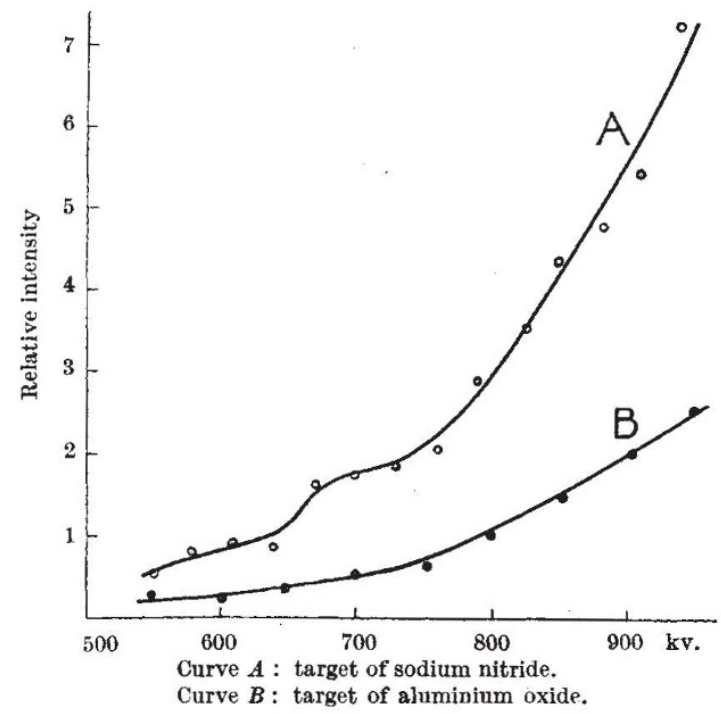

Experiments were carried out to show evidence of the process involving the heavier isotope, ${ }^{10} \mathrm{O}$, ${ }^{15} \mathrm{~N}+{ }^{1} \mathrm{H} \rightarrow{ }^{16} \mathrm{O}+h \nu$,

but without success. The use of targets of nitrogen specially enriched with ${ }^{15} \mathrm{~N}$ might produce information concerning reaction (2).

Curve $B$ shows the excitation function of ${ }^{12} \mathrm{~F}$ of period 70 seconds, formed according to

$$
{ }^{16} \mathrm{O}+{ }^{1} \mathrm{H} \rightarrow{ }^{17} \mathrm{~F}+h \nu \text {. }
$$

This was measured in the course of the above experiments but is a result of value in itself. The curve exhibits no special features and the cross-section for the reaction at low proton energies is extremely small. The measured yield was $8.0 \times 10^{-12}$ positrons per proton at $950 \mathrm{kv}$. This small yield explains the fact that the threshold for the reaction has been given previously ${ }^{3}$ as $1.4 \times 10^{6}$ volts.

Cavendish Laboratory,

S. C. Curran.

Cambridge.

$$
\text { Jan. } 2 .
$$

1 Bethe, Phys. Rev, 55, 434 (1939).

McMillan and Livingstone, Phys. Rev., 47, 452 (1935).

${ }^{2}$ Du Bridge, Barnes and Buck, Phys. Rev., 51, 995 (1937).

\section{Flame and Arc Spectra of some Calcium and Strontium Salts}

A STUDY of the flame and are spectra of ehlorides, nitrates and oxides of calcium and strontium, in the first order of $10 \mathrm{ft}$., and $21 \mathrm{ft}$., gratings, indicates that the spectra of the halides are mixed up with those of the oxides, particularly in the strontium salts; the mixed spec ra appear to be present even in spectrograms taken for the halide with are in an atmosphere of hydrogen ${ }^{1}$. This has caused many bands due to the oxide to be mistaken for $\mathrm{SrCl}$ bands. The anomalous doublet separation $\left(\sim 600 \mathrm{~cm}^{-1}\right.$ ) observed ${ }^{2}$ in $\mathrm{SrCl}$ seems to be due to such a complicated disposition of the oxide and halide bands. If the oxide bands are fully eliminated, it appears possible to arrange the bands in a system with a doublet separation of the order of $260 \mathrm{~cm}^{-1}$, which is a reasonable extrapolation for the expected doublet level. Work is in progress and a detailed description of the spectra will be published elsewhere.

We would, however, like to note another interesting characteristic feature of these spectra. Calcium salts give a narrow group of bands at 5552.4 A. shaded towards shorter waves, followed by an unresolved bright continuous patch, the intensity being high in the flame and low in the arc. This is the band also recorded by Eder and Valentas. Similarly, the spectra of strontium salts show a number of weak and strong bands shaded towards shorter waves, starting from $6113 \cdot 7 \mathrm{~A}$., followed by an unresolved bright continuous doublet patch with maxima at $16499 \mathrm{~cm} .^{-1}$, and $16548 \mathrm{~cm} .^{-1}$, which again is weak in the arc. While the details of the structure of the bands cannot, at the moment, be fully explained, it seems likely that these bands are due to the metal molecules $\mathrm{Ca}_{2}$ and $\mathrm{Sr}_{2}$, and that the electronic transition responsible for band emission involves a lower electronic state with a shallow minimum characteristic of a van der Waals type of molecule. The bands start in calcium and strontium at $18005 \mathrm{~cm}^{-1}$ and $16352 \mathrm{~cm} .^{-1}$, while the ${ }^{3} D_{3}$ states of the two atoms ${ }^{4}$ are $20371 \mathrm{~cm}^{-1}$ and $18320 \mathrm{~cm}^{-1}$ respectively above the ground levels.

Physics Department,

R. K. Asundi.

Benares Hindu University, Benares.

Department of Chemical Technology,

B. K. VAIDYa.

University of Bombay, Bombay.

Jan. 4.

${ }^{1}$ Parker, A. E., Phys. Rev., 47, 349 (1935).

${ }^{2}$ Hedfeld, K., Z. Phys., 68, 610 (1931).

"Eder, J. M., und Valenta, E., "Atlas Typischer Spektren" (Wien, 1928).

"Bacher, R. F., and Goudsmit, S., "Atomic Energy States" (New York, 1933)

\section{Red-Shifts in Nebular Spectra and Scientific Practice}

IN a recent issue of NATURE $^{1}$, Dr. K. R. Popper discusses various interpretations of the nebular redshifts. He asserts that "as basis of a measuring system for cosmological purposes" we may use, for time measurement, " $A C$ (atomic clocks)" or " $L C$ (light clocks)", implying the constancy of atomic frequencies and the velocity of light respectively; 